\title{
COMMENTARY
}

\section{Initial ventilator settings for critically ill patients}

Oguz Kilickayaa, ,2,* and Ognjen Gajic²

See related research by Fuller et al., http://ccforum.com/content/17/1/R11

\begin{abstract}
The lung-protective mechanical ventilation strategy has been standard practice for management of acute respiratory distress syndrome (ARDS) for more than a decade. Observational data, small randomized studies and two recent systematic reviews suggest that lung protective ventilation is both safe and potentially beneficial in patients who do not have ARDS at the onset of mechanical ventilation. Principles of lung-protective ventilation include: a) prevention of volutrauma (tidal volume 4 to $8 \mathrm{ml} / \mathrm{kg}$ predicted body weight with plateau pressure $<30 \mathrm{CmH}_{2} \mathrm{O}$ ); b) prevention of atelectasis (positive end-expiratory pressure $\geq 5 \mathrm{CmH}_{2} \mathrm{O}$, as needed recruitment maneuvers); c) adequate ventilation (respiratory rate 20 to 35 breaths per minute); and d) prevention of hyperoxia (titrate inspired oxygen concentration to peripheral oxygen saturation $\left(\mathrm{SpO}_{2}\right)$ levels of 88 to $95 \%$ ). Most patients tolerate lung protective mechanical ventilation well without the need for excessive sedation. Patients with a stiff chest wall may tolerate higher plateau pressure targets (approximately $35 \mathrm{CmH}_{2} \mathrm{O}$ ) while those with severe ARDS and ventilator asynchrony may require a short-term neuromuscular blockade. Given the difficulty in timely identification of patients with or at risk of ARDS and both the safety and potential benefit in patients without ARDS, lungprotective mechanical ventilation is recommended as an initial approach to mechanical ventilation in both perioperative and critical care settings.
\end{abstract}

In the previous issue of Critical Care, Fuller and colleagues [1] report the results of a systematic review on the use of lung protective (low tidal volume) mechanical ventilation in patients without acute respiratory distress syndrome (ARDS) at the onset of mechanical ventilation.

*Correspondence: kilickaya.oguz@mayo.edu

2Division of Pulmonary and Critical Care Medicine, Department of Medicine,

Mayo Clinic, Rochester, MN 55905, USA

Full list of author information is available at the end of the article
Introduction of positive pressure ventilation during a polio epidemic in 1952 resulted in a large reduction of mortality in patients with respiratory failure $(87 \%$ to less than $15 \%$ ) and marked the birth of modern intensive care medicine [2].

Better understanding of the effects of positive pressure ventilation on respiratory physiology and mechanics has led to an appreciation of potential side effects of positive pressure ventilation, in particular ventilator-associated lung injury [3]. The key determinants of ventilator-associated lung injury are cyclic alveolar distension (volutrauma) and recruitment/derecruitment (atelectrauma), the size of available lung ('baby lung'), with an additional contribution from preexisting sepsis, vascular pressures, respiratory rate and inspiratory flow [3]. Avoiding high tidal volume ventilation is the only intervention with convincing survival benefit in patients with ARDS [4]. More recently, observational studies and a randomized clinical trial suggested a benefit of avoiding conventional high tidal volume ventilation in all critically ill patients $[5,6]$.

The systematic review by Fuller and colleagues [1] highlights the importance of the low tidal volume ventilation strategy in patients without ARDS at the onset of mechanical ventilation. The results from 8 out of 13 studies included in the final analysis of this systematic review show that lower tidal volumes at initiation of mechanical ventilation reduce progression to ARDS. Similar findings were reported in another recent systematic review that combined observational studies and clinical trials in both ICUs and perioperative settings [7]. Neither of these systematic reviews raised concerns about the safety of low tidal volume ventilation in patients without ARDS.

Given the difficulty of identifying patients with ARDS in a timely fashion and both the safety and potential benefit of low tidal volume ventilation in patients without ARDS, the question arises whether conventional high tidal volume ventilation should ever be used in critical care or perioperative settings $[8,9]$.

High tidal volume ventilation was recommended in operating rooms in the early 1970 s to prevent atelectasis [10]. However, later studies did not support this approach and the focus has shifted towards the role of positive 


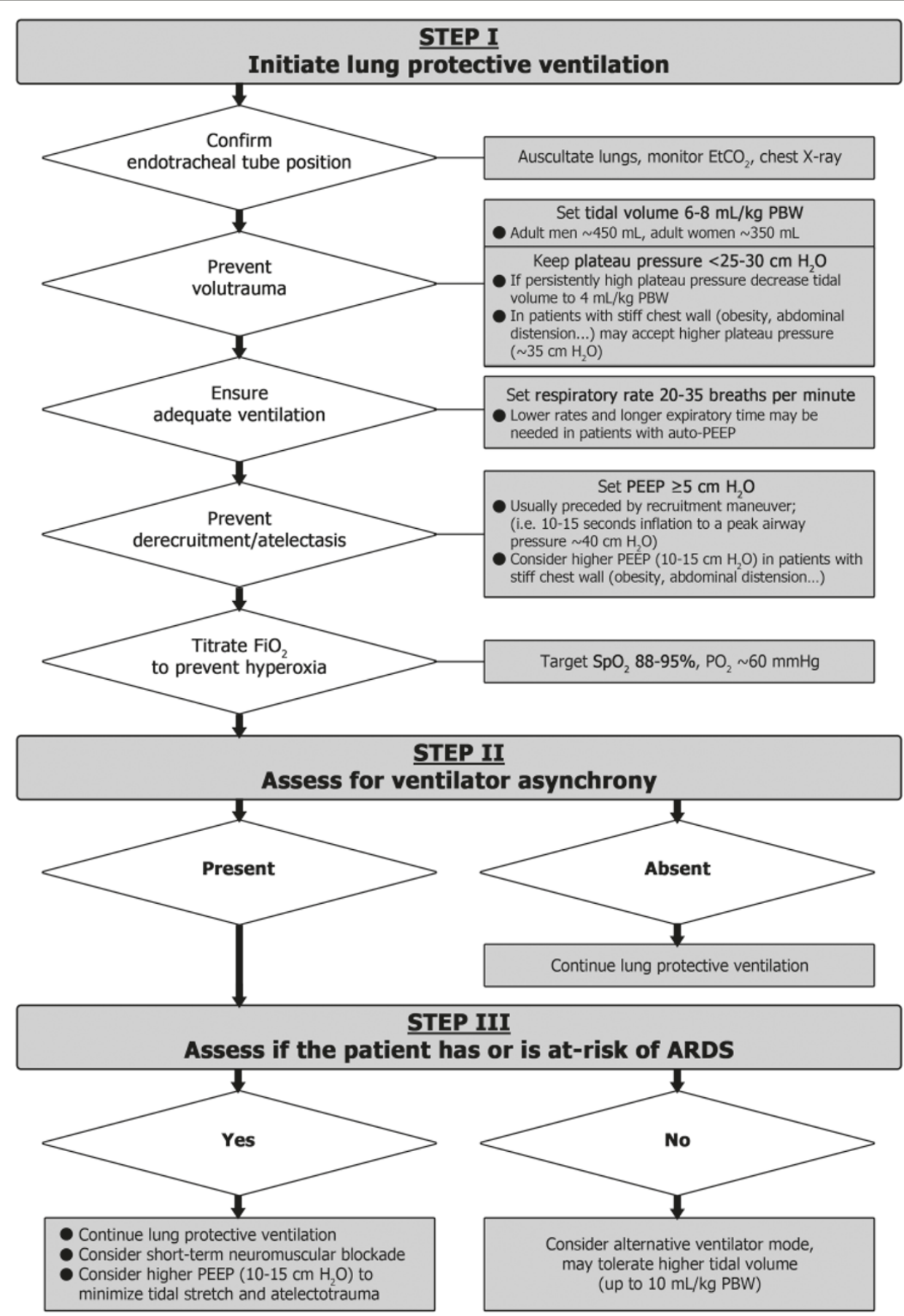

Figure 1. How to set the ventilator in perioperative and critical care settings. ARDS, acute respiratory distress syndrome; EtCO ${ }_{2}$, end-tidal carbon dioxide; $\mathrm{FiO}_{2^{\prime}}$, fraction of inspired $\mathrm{O}_{2^{\prime}} \mathrm{PBW}$, predicted body weight; $\mathrm{PEEP}$, positive end expiratory pressure; $\mathrm{PO}_{2^{\prime}}$ oxygen partial pressure; $\mathrm{SpO} 2^{\prime}$ peripheral oxygen saturation.

end-expiratory pressure, recruitment maneuvers, and the avoidance of a high fraction of inspired $\mathrm{O}_{2}\left(\mathrm{FiO}_{2}\right)$ as safer and more effective ways to prevent atelectasis than high tidal volume $[11,12]$.

The second concern with regards to low tidal volume ventilation is the increase of the carbon dioxide partial pressure $\left(\mathrm{PCO}_{2}\right)$, but acidosis is usually easily corrected by increasing respiratory rate except in patients with severe ARDS, where permissive hypercapnia may actually be desirable [13]. Another concern regarding low tidal volume ventilation is the potential increase in the need for sedation [14]. However, there is little evidence to 
support this claim, particularly in patients without ARDS [15].

Although limited, the current evidence, including the current report by Fuller and colleagues [1], suggests that the risk/benefit ratio of low tidal volume ventilation in patients with or without ARDS is on the side of benefit. In Figure 1 we provide a pragmatic approach to lung protective mechanical ventilation in patients with and without ARDS.

\section{Abbreviations}

ARDS, acute respiratory distress syndrome.

\section{Competing interests}

The authors have no financial or other potential conflicts of interest to disclose.

\section{Acknowledgements}

We thank Dr Rolf D Hubmayr and Mrs Ann Johnson for their thoughtful review and feedback.

\section{Author details}

'Department of Anesthesiology and Reanimation, Gulhane Military Medical Faculty, Ankara, Turkey. 'Division of Pulmonary and Critical Care Medicine,

Department of Medicine, Mayo Clinic, Rochester, MN 55905, USA.

Published: 12 March 2013

\section{References}

1. Fuller B, Mohr N, Drewry A, Carpenter C: Lower tidal volume at initiation of mechanical ventilation may reduce progression to acute respiratory distress: a systematic review. Crit Care 2013, 17:R11.

2. Trubuhovich RV: Further commentary on Denmark's 1952-53 poliomyelitis epidemic, especially regarding mortality; with a correction. Acta Anaesth Scand 2004, 48:1310-1315.

3. Dreyfuss D, Saumon G: Ventilator-induced lung injury: lessons from experimental studies. Am J Respir Crit Care Med 1998, 157:294-323.

4. Ventilation with lower tidal volumes as compared with traditional tidal volumes for acute lung injury and the acute respiratory distress syndrome.
The Acute Respiratory Distress Syndrome Network. N Engl J Med 2000, 342:1301-1308.

5. Yilmaz M, Keegan MT, Iscimen R, Afessa B, Buck CF, Hubmayr RD, Gajic O: Toward the prevention of acute lung injury: protocol-guided limitation of large tidal volume ventilation and inappropriate transfusion. Crit Care Med 2007, 35:1660-1666; quiz 1667.

6. Determann RM, Royakkers A, Wolthuis EK, Vlaar AP, Choi G, Paulus F, Hofstra JJ, de Graaff MJ, Korevaar JC, Schultz MJ: Ventilation with lower tidal volumes as compared with conventional tidal volumes for patients without acute lung injury: a preventive randomized controlled trial. Crit Care 2010, 14:R1.

7. Serpa Neto A, Cardoso SO, Manetta JA, Pereira VG, Esposito DC, Pasqualucci Mde O, Damasceno MC, Schultz MJ: Association between use of lungprotective ventilation with lower tidal volumes and clinical outcomes among patients without acute respiratory distress syndrome: a metaanalysis. JAMA 2012, 308:1651-1659.

8. Herasevich V, Yilmaz M, Khan H, Hubmayr RD, Gajic O: Validation of an electronic surveillance system for acute lung injury. Intensive Care Med 2009, 35:1018-1023.

9. Lellouche F, Lipes J: Prophylactic protective ventilation: lower tidal volumes for all critically ill patients? Intensive Care Med 2013, 39:6-15.

10. Visick WD, Fairley HB, Hickey RF: The effects of tidal volume and endexpiratory pressure on pulmonary gas exchange during anesthesia. Anesthesiology 1973, 39:285-290.

11. Bardoczky Gl, Yernault JC, Houben JJ, d'Hollander AA: Large tidal volume ventilation does not improve oxygenation in morbidly obese patients during anesthesia. Anesth Analg 1995, 81:385-388.

12. Rothen HU, Sporre B, Engberg G, Wegenius G, Hogman M, Hedenstierna G: Influence of gas composition on recurrence of atelectasis after a reexpansion maneuver during general anesthesia. Anesthesiology 1995, 82:832-842.

13. Laffey JG, Kavanagh BP: Carbon dioxide and the critically ill - too little of a good thing? Lancet 1999, 354:1283-1286.

14. Marini JJ: Lower tidal volumes for everyone: principle or prescription? Intensive Care Med 2013, 39:3-5.

15. Wolthuis EK, Veelo DP, Choi G, Determann RM, Korevaar JC, Spronk PE, Kuiper MA, Schultz MJ: Mechanical ventilation with lower tidal volumes does not influence the prescription of opioids or sedatives. Crit Care 2007, 11:R77.

doi:10.1186/cc12516

Cite this article as: Kilickaya O, Gajic O: Initial ventilator settings for critically ill patients. Critical Care 2013, 17:123. 